\title{
Análise Da Utilização De Endurecedores Na Dureza Superficial De Concretos Para Pisos
}

\author{
Analysis of the Use of Hardeners in Surface Hardness of Concretes for Floors
}

\author{
Francine Padilha ${ }^{1}$ (D) orcid.org/0000-0001-8662-628X \\ Beatriz Schimelfenig ${ }^{1}$ (D) orcid.org/0000-0002-1930-2055 \\ Cristina Vitorino da Silva ${ }^{1}$ (D) orcid.org/0000-0002-3073-676X \\ ${ }^{1}$ Universidade Regional Integrada do Alto Uruguai e das Missões, Erechim, Brasil. \\ E-mail do autor principal: Francine Padilha francine.padilha1609@gmail.com
}

\section{Resumo}

O constante crescimento do setor de pisos de concreto resulta no aumento da demanda por novas técnicas de aperfeiçoamento do uso deste material. Assim, quando a aplicação concerne a pisos de concreto, devem ser consideradas algumas propriedades, como a dureza superficial e as resistências mecânicas. Entretanto, tais propriedades acabam muitas vezes comprometidas, principalmente, em decorrência de problemas vinculados ao projeto, à execução e à dosagem do concreto destas estruturas. Em virtude do exposto, podem ocorrer manifestações patológicas, dentre as quais encontram-se o desgaste superficial por abrasão e a fissuração do compósito. Diante disso, este estudo irá avaliar alguns fatores como a relação água/cimento $(0,40 ; 0,50 ; 0,60)$ e o emprego de endurecedor superficial (endurecedor cimentício e líquido) no cimento CP V-ARI. Foram realizados ensaios de avaliação de resistência à compressão uniaxial, resistência à tração na flexão, exsudação e dureza superficial por esclerometria e os resultados indicam que o uso dos endurecedores superficiais cimentício e líquido tendem a aumentar a resistência superficial dos compósitos. Concluise que relações a/c maiores resultam em concretos com menor resistência e dureza superficial, e que o uso de endurecedores superficiais melhora a camada superficial dos compósitos podendo evitar possíveis manifestações patológicas.

Palavras-Chave: Pisos de Concreto; Dureza Superficial; Manifestações Patológicas; Endurecedor Superficial.

\footnotetext{
Abstract

The constant growth on concrete floors sector results on an increasing demand for new techniques to improve the use of this material. Thus, when the application concerns concrete floors, some properties must be considered, as the surface hardness and mechanical strength. However, these properties can sometimes be compromised, mainly as the result of problems related to project, execution and dosage of concrete on these structures. Because of that, there may be some 129

http: / / dx.doi.org/10.25286/repa.v2i3.704
} 
pathological manifestations among which are the surface abrasion wear and the cracking of the composite. Therefore, this study aims to evaluate some factors such as the water/binder ratio (0.40; $0.50 ; 0.60)$, the use of surface hardener (cement and liquid hardener), with CP V-ARI cement. The tests of compressive strength, flexural tensile strength, bleeding and surface hardness by sclerometry are the form of evaluation and the results indicate that the use of cement and liquid surface hardeners tend to increase the surface resistance of composites. It is concluded that higher water / binder ratio results in concretes with lower strength and surface hardness, and that the use of surface hardeners improves the surface layer of the composites and can avoid possible pathological manifestations.

Key-words: Concrete Floors; Surface Hardness; Pathological Manifestations; Surface Hardener.

\section{Introdução}

O concreto é um dos materiais de construção mais utilizados em todo o mundo, o que salienta a elevada importância de novas pesquisas tecnológicas nessa área. Devido a essa elevada empregabilidade, o concreto está sujeito a situações que podem gerar manifestações patológicas, capazes de prejudicar fatores muito importantes, como durabilidade e resistência, o que contribui para a redução da vida útil das estruturas [1].

Para Farny (2001), propriedades como durabilidade, dureza, resistência química, resistência ao impacto e resistência à abrasão são os principais atributos dos pisos de concreto [2]. No entanto, tais propriedades acabam muitas vezes comprometidas, principalmente em função de problemas vinculados ao projeto, à execução e à dosagem do concreto dessas estruturas [3]. Diante disso, podem ocorrer manifestações patológicas, sendo as mais frequentes em pisos de concreto: fissuração, desgaste superficial por abrasão, empenamento, borrachudo, delaminação, esborcinamento das juntas e descoloração [4; 5].

No ano de 2008, dos 35 milhões de $\mathrm{m}^{2}$ de pisos e pavimentos de concreto produzidos no Brasil, em torno de 22,5 milhões de $\mathrm{m}^{2}$ apresentaram alguma manifestação patológica vinculada às falhas, tanto no projeto de pisos como na execução destes. Portanto, aproximadamente $65 \%$ dos pisos e pavimentos de concreto produzidos em 2008 apresentaram algum tipo de manifestação patológica [1].

Segundo Almeida (2000), a resistência dos concretos ao desgaste por abrasão é regida por vários fatores, tais como a natureza do aglomerante, a relação água/aglomerante, as características do agregado graúdo, dosagem e aderência entre os agregados e a pasta de cimento. Interferem também as características do concreto no estado fresco (segregação, exsudação, trabalhabilidade e teor de ar incorporado), a compactação, a cura e o acabamento e tratamento superficial [6].

Este estudo tem como objetivo principal buscar uma melhoria na qualidade dos compósitos e na dureza superficial, a fim de minimizar a tendência do aparecimento de manifestações patológicas, como o desgaste por abrasão. Por conseguinte, avaliar a influência do uso de tratamentos superficiais com endurecedores e a influência de diferentes relações água/cimento ( $\mathrm{a} / \mathrm{c})$, frente aos ensaios mecânicos e de dureza superficial. Para isto, foram avaliados dois tipos de endurecedores superficiais (líquido; cimentício) e três relações água/cimento $(0,40 ; 0,50$; $0,60)$.

\section{Manuscrito}

Segundo o ACI 302.1R (ACI, 2004), a qualidade de um piso de concreto está diretamente associada à existência de uma superfície de elevada dureza e durabilidade, plana e relativamente livre de fissuras, que esteja em conformidade com um nível de referência, e que possua uma textura superficial adequada à futura utilização do piso [5].

A exsudação é uma propriedade de extrema importância na execução de pisos de concreto, uma vez que a camada exsudada que se forma na superfície é mais fraca que o restante do concreto, tornando-se mais favorável ao surgimento do desgaste superficial. Quando em excesso leva a um enfraquecimento da ligação entre a matriz de cimento e a superfície dos agregados (zona de transição), 
reduzindo a resistência do concreto e propiciando a formação de vazios capilares, o que compromete a durabilidade do material [3].

Segundo Neville (1997), o ensaio esclerométrico, além de servir para estimar a resistência à compressão do concreto, é utilizado para a determinação de propriedades da superfície do material, as quais têm uma influência direta em seu desempenho, como por exemplo, na resistência à abrasão de pisos de concreto [7].

Uma grande parcela dos pisos de concreto, ao serem executados, não recebe nenhum tipo de revestimento como forma de acabamento, sendo então, a resistência à abrasão do concreto um dos parâmetros mais importantes para garantir uma adequada vida útil e uma baixa manutenção a essas estruturas [8]. Para os mesmos autores, o desgaste acentuado da superfície do piso pode trazer inúmeros problemas aos usuários, desde um simples desconforto estético até grandes transtornos com relação à redução da funcionalidade da estrutura.

Assim, quando estes fenômenos ocorrem, agregados especiais ou tratamentos de superfície são necessários, como por exemplo, endurecedores líquidos ou endurecedores cimentícios à base de agregados minerais ou metálicos, os quais podem ser adicionados à superfície [8; 9]. A utilização destes materiais produz uma camada superficial eficiente, altamente resistente ao desgaste e ao impacto [9]. A eficiência do incremento de resistência à abrasão está relacionada com a profundidade de penetração desses endurecedores [8].

\section{Programa Experimental}

Visando verificar a influência da relação a/c e o uso dos endurecedores de superfície, esta pesquisa foi realizada sempre com a pretensão de reproduzir as condições usuais adotadas na produção de pisos de concreto. A escolha da relação água/cimento se deu devido à relação 0,5 ser comumente utilizada em projetos de pisos de concreto. Portanto, optou-se por avaliar características dos concretos com relação inferior $(0,4)$ e superior $(0,6)$.

Para o tratamento superficial do concreto, foram avaliados dois materiais distintos; endurecedor cimentício a base de agregados minerais e endurecedor líquido químico a base de silicato de lítio, silicato de sódio e nanosílica, fornecidos por um mesmo fabricante. A aplicação do endurecedor liquido 131 é feito através de pulverizador costal de baixa pressão ou regador, diretamente sobre a superfície cimentícia em movimentos simétricos e com ligeira sobreposição de camadas, com consumo médio de $200 \mathrm{~L} / \mathrm{m}^{2}$. No endurecedor cimentício, a aplicação é feita por aspersão manual, e a taxa de aplicação recomendada varia de 4 a $9 \mathrm{~kg} / \mathrm{m}^{2}$.

Os ensaios que embasaram as análises da dureza superficial foram os ensaios de esclerometria e exsudação. Para a análise da resistência e o controle tecnológico dos concretos foram realizados os ensaios de resistência à compressão uniaxial e resistência à tração na flexão.

\subsection{Materiais Utilizados}

A caracterização dos materiais utilizados na produção dos concretos, foi obtida segundo as suas respectivas normas, sendo a seguinte:

- Cimento: Portland CP V-ARI, com massa específica igual a $3,06 \mathrm{~g} / \mathrm{cm}^{3}$;

- Agregado miúdo: areia natural, dimensão máxima característica (DMC) igual a $1,18 \mathrm{~mm}$, com módulo de finura (MF) igual a $1,47 \mathrm{e}$ massa específica igual a $2,62 \mathrm{~g} / \mathrm{cm}^{3}$;

- Agregados graúdos: brita de origem basáltica, denominada comercialmente como brita 1 , com as seguintes características: MF $(6,91)$ e DMC (19 mm) e massa específica igual a 2,57 $\mathrm{g} / \mathrm{cm}^{3}$;

- Aditivo: superplastificantes baseado em uma cadeia de éter policarboxílico;

- A água utilizada para a produção dos concretos foi proveniente da rede de abastecimento pública de Erechim (RS).

\subsection{Dosagem Experimental}

O método de dosagem utilizado para este estudo foi o IPT/EPUSP, proposto por Helene e Terzian [10], cujos parâmetros utilizados foram a obtenção de um abatimento de tronco de cone de $100 \pm 20 \mathrm{~mm}$, definido com base em especificações de projeto para pisos de concreto. Através deste método, determinouse experimentalmente um teor de argamassa de 54\% como sendo o ideal. A Tabela 1 especifica os valores

http: / /dx.doi.org/10.25286/repa.v2i3.704 
da dosagem experimental realizada para o cimento de alta resistência inicial (CP V-ARI).

Tabela 1: Resultados da dosagem experimental.

\begin{tabular}{c|c|c|c|c}
\hline $\begin{array}{c}\text { Traço } \\
\text { unitário } \\
(\mathbf{1 : m})\end{array}$ & $\begin{array}{c}\text { Relação } \\
\text { a/c }\end{array}$ & $\begin{array}{c}\text { Resistência } \\
\mathbf{2 8} \text { dias } \\
\text { (MPa) }\end{array}$ & $\begin{array}{c}\text { Consumo } \\
\text { Cimento } \\
\left(\mathbf{k g} / \mathbf{m}^{3}\right)\end{array}$ & $\begin{array}{c}\mathbf{H} \\
\mathbf{( \% )}\end{array}$ \\
\hline $1: 3,5$ & 0,44 & 39,28 & 466 & 9,7 \\
\hline $1: 5$ & 0,51 & 30,78 & 357 & 8,5 \\
\hline $\begin{array}{c}1: 6,5 \\
\text { Relação água/materiais secos, H (\%). }\end{array}$ & 0,66 & 19,93 & 284 & 8,7 \\
\end{tabular}

Após a realização das dosagens experimentais e com o auxílio das curvas de dosagem foram determinados os traços dos concretos. A Tabela 2 apresenta a definição dos parâmetros dos traços que foram empregados nesta pesquisa.

Tabela 2: Parâmetros dos traços empregados.

\begin{tabular}{|c|c|c|c|c|c|}
\hline $\begin{array}{c}\text { Relação } \\
\text { a/c }\end{array}$ & Traço & $\begin{array}{l}\text { Lei de } \\
\text { Lise }\end{array}$ & $\underset{(a+p)}{m}$ & $\begin{array}{c}\text { Traço } \\
\text { unitário }\end{array}$ & $\begin{array}{r}\text { Consumo } \\
\text { Cimento } \\
\left(\mathrm{kg} / \mathrm{m}^{3}\right)\end{array}$ \\
\hline 0,4 & $1 \mathrm{~B}$ & \multirow{3}{*}{$\begin{array}{l}66,533 \mathrm{e}^{-} \\
1,48(\mathrm{a} / \mathrm{c})\end{array}$} & 3 & $1: 1,16: 1,84$ & 522,00 \\
\hline 0,5 & $2 B$ & & 3,93 & $1: 1,66: 2,27$ & 421,29 \\
\hline 0,6 & $3 B$ & & 4,86 & $1: 2,17: 2,70$ & 353,15 \\
\hline
\end{tabular}

\subsection{Métodos de Ensaio}

Os ensaios que embasarão as análises da dureza superficial serão os ensaios de dureza superficial por esclerometria e exsudação. Para análise da resistência e controle tecnológico dos concretos serão realizados os ensaios de resistência à compressão uniaxial e resistência à tração na flexão. Os resultados obtidos em todos os ensaios foram submetidos à análise estatística através da análise de variância (ANOVA) do programa Statistica 7.0.

O método de ensaio de resistência à compressão de corpos de prova cilíndricos de concreto seguiu as determinações da norma brasileira NBR 5739 ABNT de 2007 [11]. Após a moldagem, os CP's foram cobertos por um plástico, não reativos e não absorvente, com a finalidade de evitar a perda de água do concreto para o ambiente externo. Estes foram armazenados em superfície horizontal rígida e em ambiente livre da ação de intempéries, durante as primeiras 24 horas. Após esta etapa, os CP's foram desmoldados e mantidos a cura úmida (UR > $95 \%$ e temperatura de $23 \pm 2^{\circ} \mathrm{C}$ ) até a idade de 28 dias para a realização do ensaio.

O ensaio de resistência à tração na flexão foi realizado de acordo com a norma brasileira NBR 12142 ABNT de 2010 [12]. Foram ensaiados dois corpos de prova à tração na flexão, aos 28 dias, para cada traço de concreto do programa experimental. Foi empregada a mesma metodologia para a cura inicial, desforma e cura úmida, conforme descrito anteriormente no ensaio de resistência à compressão.

Os ensaios de exsudação foram realizados com o concreto no estado fresco conforme NBR 15558 ABNT de 2008 [13], sendo realizadas duas repetições para cada traço analisado. A fôrma utilizada é de PVC com dimensões reduzidas, porém respeitando-se o proporcionamento entre diâmetro e altura especificados na norma. Salienta-se que o adensamento do molde para todos os traços ensaiados foi manual. O ensaio de exsudação foi realizado em câmera climatizada com temperatura e umidade constantes (UR $70 \pm 10 \%$ e temperatura de $\left.23 \pm 2^{\circ} \mathrm{C}\right)$.

O método de avaliação da dureza superficial por esclerometria fornece elementos para avaliação da qualidade do concreto endurecido através do índice esclerométrico. Este tem como princípio de funcionamento a ação de uma massa ou martelo, que impulsionada por uma mola se choca com o concreto, o esclerômetro então registra a energia remanescente do impacto [3].

Para o ensaio de dureza foram produzidas placas de concreto de $250 \mathrm{~mm}$ x $250 \mathrm{~mm} \times 100 \mathrm{~mm}$ de espessura, sendo utilizadas formas de compensado plastificado para a moldagem das placas. Foram moldadas duas placas para cada tipo de tratamento superficial aplicado, sendo que em cada uma das placas foram realizados 16 impactos, sendo estes, distribuídos de forma homogênea na superfície conforme NBR 7584 ABNT de 1995 [14].

\section{Análise e Discussão dos Resultados 4.1 Resistência à compressão uniaxial e tração na flexão}

A Tabela 3 apresenta os resultados médios obtidos no ensaio de resistência à compressão uniaxial e a Tabela 4 apresenta os resultados médios no ensaio de resistência à tração na flexão para os concretos com CP V-ARI. 
Tabela 3: Resultados para ensaio de resistência à compressão uniaxial.

\begin{tabular}{c|c|c|c}
\hline Traço & $\begin{array}{c}\text { Médias } \\
(\mathbf{M P a})\end{array}$ & Desvio Padrão & $\begin{array}{c}\text { Coeficiente de } \\
\text { Variância (\%) }\end{array}$ \\
\hline 1B & 44,83 & 2,61 & 5,83 \\
\hline 2B & 37,67 & 0,83 & 2,20 \\
\hline 3B & 33,86 & 1,51 & 4,45
\end{tabular}

Tabela 4: Resultados para ensaio de resistência à tração na flexão.

\begin{tabular}{c|c|c|c}
\hline Traço & $\begin{array}{c}\text { Médias } \\
(\mathrm{MPa})\end{array}$ & Desvio Padrão & $\begin{array}{c}\text { Coeficiente de } \\
\text { Variância (\%) }\end{array}$ \\
\hline 1B & 5,93 & 0,12 & 2,02 \\
\hline 2B & 5,28 & 0,22 & 4,08 \\
\hline 3B & 4,98 & 0,06 & 1,20
\end{tabular}

Os resultados foram analisados estatisticamente através do método de análise de variância (ANOVA). Tal análise buscou avaliar se a relação a/c causa efeito significativo na resistência à compressão uniaxial e na resistência à tração na flexão. Estas análises dos dados experimentais obtidos para a resistência à compressão uniaxial encontram-se na Tabela 5 e resistência à tração na flexão dos concretos estudados encontram-se na Tabela 6.

Tabela 5: Análise de variância (ANOVA) - resistência à compressão uniaxial.

\begin{tabular}{l|c|c|c|c|c|c}
\hline & SS & GLD & MS & $\begin{array}{c}\text { F } \\
\text { (calc) }\end{array}$ & P & S \\
\hline Relação a/c & 241,12 & 2 & 120,56 & 17,634 & 0,00077 & S \\
\hline Erro & 61,53 & 9 & 6,84 & & & \\
\hline
\end{tabular}

GDL: graus de liberdade ( $n-1) ;$ MS: média simples; $F($ calc): valor calculado de F; P: nível de significância; $S$ : valor significativo; NS: valor não significativo; Se $\mathrm{P}<5 \%$ valor significativo.

Tabela 6: Análise de variância (ANOVA) - resistência à tração na flexão.

\begin{tabular}{l|c|c|c|c|c|c}
\hline & SS & GLD & MS & $\begin{array}{c}\text { F } \\
\text { (calc) }\end{array}$ & P & S \\
\hline $\begin{array}{l}\text { Relação } \\
\text { a/c }\end{array}$ & 1,1989 & 2 & 0,5995 & 157,06 & 0,00092 & S \\
\hline Erro & 0,0114 & 3 & 0,0038 & & & \\
\hline
\end{tabular}

GDL: graus de liberdade ( $n-1)$; MS: média simples; $F($ calc): valor calculado de F; P: nível de significância; S: valor 133 significativo; NS: valor não significativo; Se $\mathrm{P}<5 \%$ valor significativo.

A análise estatística dos dados de resistência à compressão uniaxial indicou que a relação a/c gerou influência significativa nessa propriedade. Comportamento similar foi verificado na resistência à tração na flexão. A Figura 1 mostra a influência da relação a/c sobre a resistência à compressão uniaxial e a Figura 2 a influência da relação a/c sobre a resistência à tração na flexão dos concretos ensaiados.

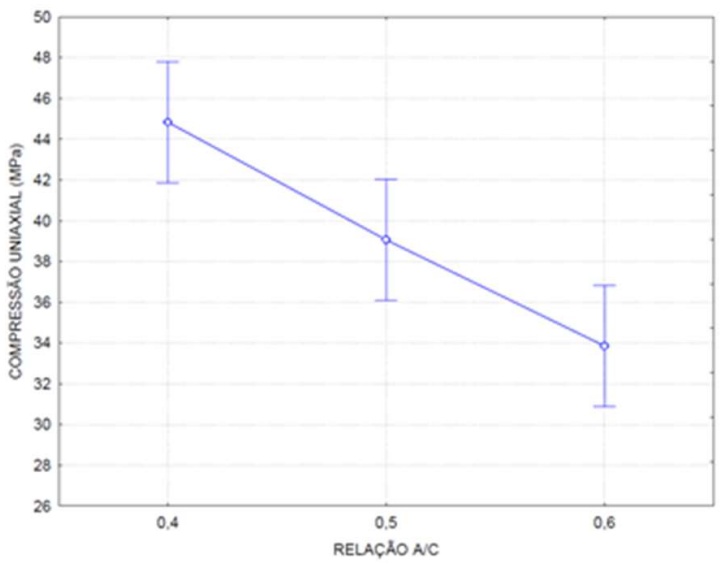

Figura 1: Efeito da relação a/c na resistência à compressão uniaxial.

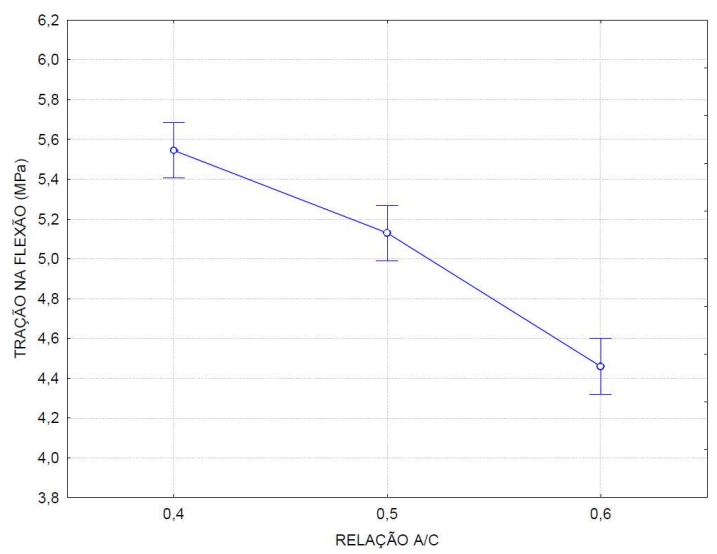

Figura 2: Efeito da relação a/c na resistência à tração na flexão.

Através da análise do gráfico verifica-se, conforme esperado, uma redução significativa na resistência à compressão e na resistência à tração na flexão dos concretos produzidos com maior relação a/c em comparação aos compósitos com menor relação a/c. Este comportamento ocorre em função do acréscimo http: / / dx.doi.org/10.25286/repa.v2i3.704 
da porosidade na pasta e na zona de transição pastaagregado, e pela presença de cristais de $\mathrm{Ca}(\mathrm{OH})_{2}$ orientados e mais desenvolvidos com o aumento da relação a/agl [7; 15].

\subsection{Exsudação}

Os resultados do ensaio de exsudação encontramse na Tabela 7.

Tabela 7: Resultados para ensaio de exsudação.

\begin{tabular}{c|c|c|c}
\hline Traço & $\begin{array}{c}\text { Médias } \\
(\mathbf{M P a})\end{array}$ & Desvio Padrão & $\begin{array}{c}\text { Coeficiente de } \\
\text { Variância (\%) }\end{array}$ \\
\hline 1B & 1,27 & 0,07 & 5,51 \\
\hline 2B & 2,36 & 0,11 & 4,46 \\
\hline 3B & 3,26 & 0,09 & 2,61
\end{tabular}

Conforme mostrado na Tabela 7, os percentuais de água exsudada ficaram dentro do permitido para pisos industriais de concreto, que não deve exceder $4 \%$ [5]. Os resultados foram analisados estatisticamente através do método de análise de variância (ANOVA). Tal análise buscou avaliar se a relação a/c causa efeito significativo na exsudação dos compósitos. A análise de variância feita através da ANOVA dos dados experimentais obtidos para a exsudação dos concretos estudados encontra-se na Tabela 8.

Tabela 8: Análise de variância (ANOVA) - exsudação.

\begin{tabular}{l|c|c|c|c|c|c}
\hline & SS & GLD & MS & $\begin{array}{c}\text { F } \\
\text { (calc) }\end{array}$ & P & S \\
\hline $\begin{array}{l}\text { Relação } \\
\text { a/c }\end{array}$ & 3,95163 & 2 & 1,97582 & 128,023 & 0,001246 & S \\
\hline Erro & 0,04630 & 3 & 0,01543 & & & \\
\hline
\end{tabular}

GDL: graus de liberdade $(n-1)$; MS: média simples; $F($ calc): valor calculado de $\mathrm{F}$; $\mathrm{P}$ : nível de significância; $\mathrm{S}$ : valor significativo; NS: valor não significativo; Se $\mathrm{P}<5 \%$ valor significativo.

A análise estatística dos dados de exsudação indicou que a relação a/c gerou influência significativa nessa propriedade. A Figura 3 mostra a influência da relação a/c sobre a exsudação dos concretos ensaiados.

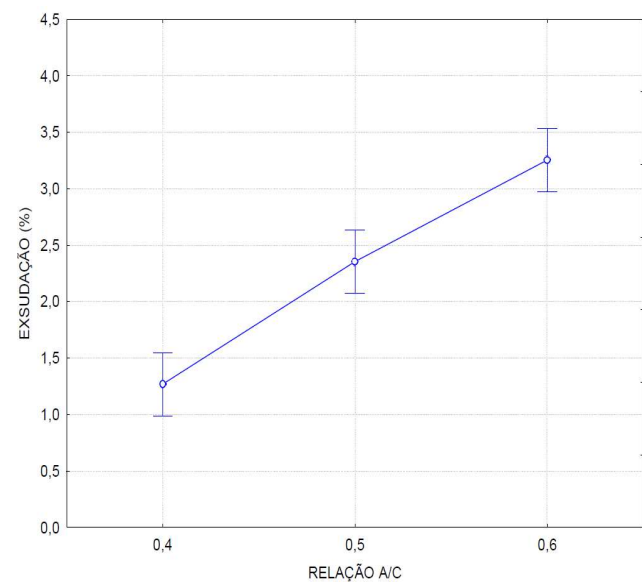

Figura 3: Efeito da relação a/c na exsudação do concreto.

O comportamento obtido no ensaio de exsudação foi o esperado, apresentando um acréscimo na quantidade de água exsudada para relações a/c maiores. Um concreto com alta relação a/c pode levar a segregação dos materiais constituintes e promover exsudação excessiva, carreando material mais frágil para a superfície [5].

\subsection{Dureza Superficial por Esclerometria}

Os resultados médios obtidos para o ensaio da dureza superficial dos concretos estudados encontram-se na Tabela 9.

Tabela 9: Resultados para o ensaio de dureza superficial por esclerometria.

\begin{tabular}{l|l|c|c|c}
\hline \multirow{2}{*}{ Traço } & $\begin{array}{c}\text { Tratamento } \\
\text { Superficial }\end{array}$ & $\begin{array}{c}\text { Médias } \\
\mathbf{( \% )}\end{array}$ & $\begin{array}{c}\text { Desvio } \\
\text { Padrão }\end{array}$ & $\begin{array}{c}\text { Coeficiente } \\
\text { Variância (\%) }\end{array}$ \\
\hline \multirow{4}{*}{ 1B } & Sem Enducedor & 46,83 & 0,65 & 1,40 \\
\cline { 2 - 5 } & End. Cimentício & 52,01 & 0,22 & 0,43 \\
\cline { 2 - 5 } & End. Líquido & 48,87 & 0,49 & 1,00 \\
\hline \multirow{4}{*}{ 2B } & Sem Enducedor & 42,91 & 0,37 & 0,85 \\
\cline { 2 - 5 } & End. Cimentício & 46,42 & 0,72 & 1,55 \\
\cline { 2 - 5 } & End. Líquido & 43,82 & 0,54 & 1,24 \\
\hline \multirow{4}{*}{$3 B$} & Sem Enducedor & 38,01 & 0,86 & 2,25 \\
\cline { 2 - 5 } & End. Cimentício & 43,49 & 0,34 & 0,77 \\
\cline { 2 - 5 } & End. Líquido & 42,09 & 0,77 & 1,83 \\
\hline
\end{tabular}


Em todos os traços o endurecedor cimentício apresentou melhor eficácia do que o endurecedor líquido. Com o uso do endurecedor líquido a dureza superficial teve um ganho de aproximadamente $4,36 \%, 2,12 \%$ e $10,73 \%$ nos traços $1 B, 2 B$ e $3 B$, respectivamente, comparando com os concretos sem o uso de endurecedores superficiais. Para o endurecedor cimentício, esse ganho foi mais expressivo, de aproximadamente $11 \%$, 8,9\% e $14,42 \%$, nos traços $1 \mathrm{~B}, 2 \mathrm{~B}$ e $3 \mathrm{~B}$, respectivamente, comparando com os compósitos sem tratamento superficial. Os resultados foram analisados estatisticamente através do método de análise de variância (ANOVA). Tal análise buscou avaliar se a relação a/c e o tipo de tratamento superficial, e as suas interações causam efeito significativo na dureza superficial por esclerometria medida. A análise de variância feita através da ANOVA dos dados experimentais obtidos para a dureza superficial dos concretos estudados encontra-se na Tabela 10 .

Tabela 10: Análise de variância (ANOVA) - dureza superficial por esclerometria.

\begin{tabular}{l|c|c|c|c|c|c}
\hline & SS & GLD & MS & $\begin{array}{c}\text { F } \\
\text { (calc) }\end{array}$ & P & S \\
\hline $\begin{array}{l}\text { Tipo de } \\
\begin{array}{l}\text { Tratamento } \\
(1)\end{array}\end{array}$ & 57,34 & 2 & 28,67 & 80,43 & 0,000002 & S \\
\hline $\begin{array}{l}\text { Relação a/c } \\
(2)\end{array}$ & 326,56 & 2 & 163,28 & 458,04 & 0,000000 & S \\
\hline$(1)^{*}(2)$ & 13,63 & 4 & 3,41 & 9,56 & 0,002667 & S \\
\hline Erro & 3,21 & 9 & 0,36 & & & \\
\hline
\end{tabular}

GDL: graus de liberdade $(n-1) ; M S:$ média simples; $F($ calc): valor calculado de $\mathrm{F}$; P: nível de significância; S: valor significativo; NS: valor não significativo; Se $\mathrm{P}<5 \%$ valor significativo.

De acordo com a tabela, observa-se que os efeitos isolados e suas interações foram significativos na variável de resposta (dureza superficial). Os itens que seguem analisam separadamente os efeitos isolados e as interações significativas, verificadas através da análise de variância (ANOVA).

\subsubsection{Efeito da relação a/c}

A Figura 4 mostra a influência isolada da relação a/c sobre a dureza superficial dos concretos. Tal figura 135 foi obtida através dos resultados da dureza superficial dos traços estudados, na análise de variância (ANOVA).

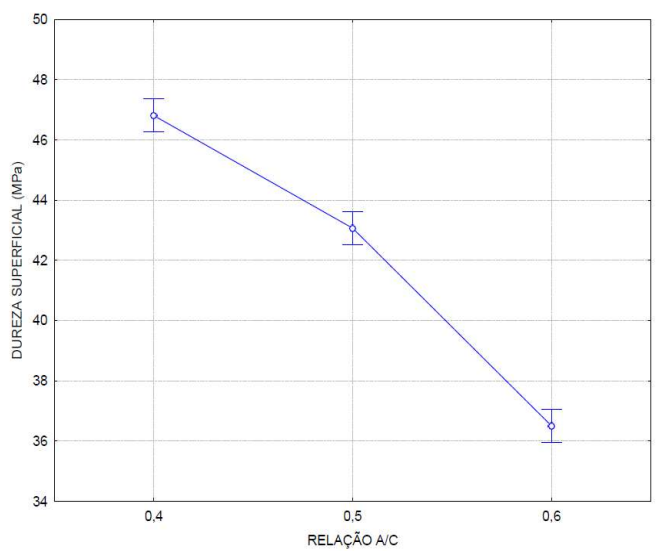

Figura 4: Efeito isolado da relação água/cimento na dureza superficial.

É possível observar um decréscimo significativo da dureza superficial para relações água/cimento mais altas $(0,5$ e 0,6). Tal resultado está correlacionado com as outras propriedades medidas, dentre elas a resistência à compressão uniaxial, na qual uma redução dos valores obtidos consequentemente diminui os valores de dureza superficial. Outra propriedade que tem grande influência na dureza superficial é a exsudação, pois quanto maior a quantidade de água exsudada, como ocorrido nos compósitos com as maiores relações a/c, mais fraca poderá ser a camada superficial, diminuindo assim a resistência da superfície. Esta redução se deve a um concreto mais poroso e menos coeso produzido pelos traços com maior relação a/c.

\subsubsection{Efeito do Tipo de Tratamento Superficial}

A Figura 5 mostra a influência isolada do tipo de tratamento sobre a dureza superficial dos concretos. Tal figura foi obtida através dos resultados da dureza superficial dos traços estudados, na análise de variância (ANOVA).

http: //dx.doi.org/10.25286/repa.v2i3.704 


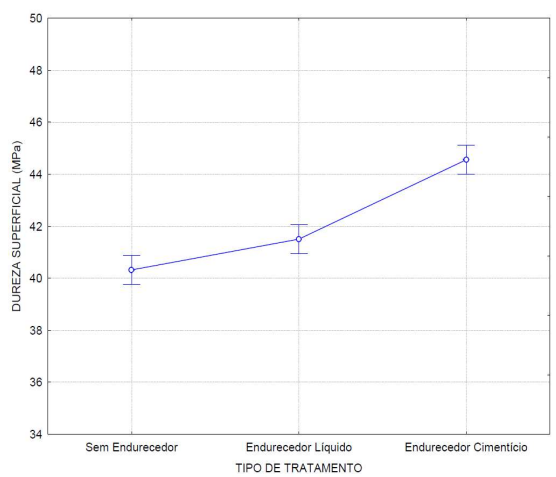

Figura 5: Efeito isolado do tipo de tratamento na dureza superficial.

A Figura 5 apresenta o comportamento da dureza superficial com aplicação de endurecedores superficiais, percebe-se que há uma tendência no aumento da dureza superficial com a utilização destes produtos, sendo que tal acréscimo é mais acentuado quando utilizado o endurecedor cimentício do que o endurecedor líquido, comportamento também visto na Tabela 9. O endurecedor cimentício é rico em sílica ativa, logo esse aglomerante possivelmente promoveu a melhora na porosidade da camada exposta, assim aumentando a resistência superficial.

\subsubsection{Efeito da Interação entre a Relação a/c e o Tipo de Tratamento Superficial}

A Figura 6 mostra o efeito combinado entre a relação a/c e o tipo de tratamento superficial. Tal figura foi obtida através dos resultados da dureza superficial dos traços estudados, na análise de variância (ANOVA).

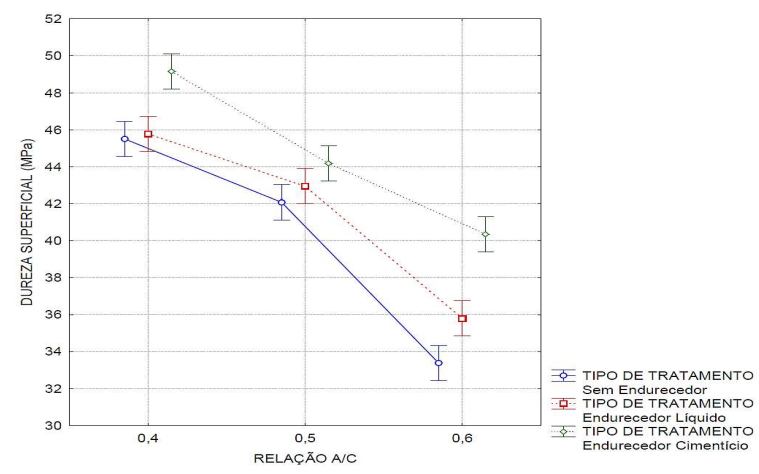

Figura 6: Efeito combinado da relação água/cimento e do tipo de tratamento na dureza superficial.
Analisando a Figura 6, verifica-se a influência significativa da interação entre a relação a/c e o tipo de tratamento superficial dos concretos. Conforme análise estatística, o efeito do tipo de tratamento sem endurecedor apresentou menores valores na dureza superficial comparando com o tratamento com endurecedor liquido e cimentício. Porém, de acordo com a análise estatística feita pelo Método de Fischer (ferramenta da ANOVA, que permite verificar se há ou não diferença significativa entre os resultados), apenas na relação a/c 0,6, ambos os endurecedores superficiais apresentaram influência significativa na dureza superficial. Na relação a/c 0,4, apenas o endurecedor cimentício causou efeito significativo na propriedade em questão. Os resultados obtidos com o endurecedor cimentício na relação a/c 0,5, estatisticamente, foram os mesmos que os obtidos para os concretos sem o uso de endurecedores superficiais com a relação a/c menor $(0,4)$, ou seja, com a utilização do endurecedor cimentício foi possível atingir os mesmos valores para a dureza superficial com maior consumo de água. Segundo este método, foi verificado também que o endurecedor líquido e o endurecedor cimentício, ambos na relação 0,5 , não se mostraram significativamente diferentes entre si.

Observa-se que para o efeito combinado da relação água/cimento e do tipo de tratamento na dureza superficial, na relação a/c 0,6, o endurecedor liquido e endurecedor cimentício apresentaram uma melhora significativa na dureza superficial, de aproximadamente $7,19 \%$ e de $21,26 \%$, respectivamente, comparando com o concreto referência sem o uso de tratamento superficial. Nesta relação $a / c$, obteve-se os maiores acréscimos na dureza superficial para cada tipo de endurecedor, este fato deve-se pelo concreto nesta relação apresentar uma maior exsudação, logo, maior capacidade de hidratação do endurecedor cimentício na camada externa. Além disso, a própria utilização deste material reduz a quantidade de água na superfície, evitando o enfraquecimento excessivo da superfície.

Para o endurecedor líquido, o aumento na dureza superficial deve-se pelo fato da superfície externa ser mais porosa nesta relação $a / c$, do que nas relações menores, assim a superfície apresenta mais poros para serem preenchidos, obtendo uma melhora mais significativa. As relações a/c menores são mais densas, menos porosas, logo a eficácia dos endurecedores não fica tão evidente. Existem endurecedores líquidos (químicos) à base de silicato 
de sódio e à base de flúorsilicato de zinco ou magnésio, que reagem com o $\mathrm{Ca}(\mathrm{OH})_{2}$ presente na pasta de cimento para formar produtos insolúveis, selando e obstruindo os poros capilares próximos ou na superfície, e com isto aumentando a resistência à abrasão [16].

Porém, no concreto com relação a/c 0,4, apenas o endurecedor cimentício apresentou melhora significativa na propriedade avaliada, comparando com o concreto sem uso de endurecedor. O endurecedor líquido não aumentou significativamente a dureza nessa relação $a / c$, fato que pode ser explicado pela baixa porosidade superficial que essa relação apresenta, dessa maneira dificultando que o endurecedor penetrasse no concreto e tivesse total eficácia.

\section{Conclusões}

Esta pesquisa teve como objetivo avaliar tanto a influência da relação água/cimento dos compósitos cimentícios, quanto do uso de endurecedores superficiais, frente a dureza superficial. Dentro desse contexto, foram analisadas diferentes relações a/c $(0,4 ; 0,5 ; 0,6)$ e diferentes tipos de tratamentos superficiais (sem endurecedor; endurecedor líquido; endurecedor cimentício). Para tal avaliação realizaram-se alguns ensaios relacionados às propriedades de superfície (exsudação e dureza superficial por esclerometria) e às propriedades da qualidade do concreto (resistência à compressão uniaxial e resistência à tração na flexão). Para avaliar a influência de cada fator nas propriedades estudadas foram efetuadas análises estatísticas.

A relação a/c influencia significativamente em todos os ensaios realizados. $\mathrm{Na}$ resistência a compressão, na resistência tração na flexão e na dureza superficial, verificou-se uma redução das resistências em todos os casos ensaiados para as maiores relações a/c. No ensaio de exsudação, quanto maior a relação a/c maior a água exsudada. Ou seja, quanto menor a proporção de água na mistura do concreto, melhor será o desempenho dos compósitos.

Quanto à dureza superficial, a relação a/c manteve o mesmo comportamento mencionado anteriormente, as maiores relações a/c apresentaram os menores valores para a dureza superficial. Quanto ao tratamento superficial, ambos os endurecedores apresentaram melhora na dureza superficial, porém foi mais eficaz quando utilizado o endurecedor cimentício do que o endurecedor líquido, comparando com concreto sem tratamento superficial. Quando analisada a interação da relação a/c e o tipo de tratamento, observou-se uma tendência de melhora na camada externa dos compósitos com a aplicação dos endurecedores, porém esse aumento na dureza superficial ficou mais evidente na relação a/c 0,6, pois nessa relação a porosidade superficial é maior, ou seja, tem mais vazios onde o endurecedor pode agir, apresentando maior eficácia.

Com esta pesquisa concluiu-se, então, que menores relações a/c tendem a proporcionar um concreto com menor exsudação, maiores resistências mecânicas e dureza superficial. Os endurecedores superficiais analisados proporcionaram um aumento no índice esclerométrico, desempenhando seu papel, porém devem ser levados em conta todos os fatores que poderiam interferir nesse desempenho para poder afirmar que sua eficiência é realmente significativa. Para tal afirmação há a necessidade de mais estudos nesta área, uma vez que tais resultados estão relacionados a compósitos que apresentam características específicas, com materiais, proporcionamentos, parâmetros de dosagem e tamanho reduzido das amostras.

\section{Referências}

[1] SENISSE, J. A. L. Influência do consumo de água, da adição de microfibras de polipropileno e do tipo de cimento nas variações dimensionais de concretos empregados em pisos. 2010. $157 \mathrm{f}$. Dissertação (Mestrado em Engenharia Civil) Escola de Engenharia, Universidade Federal do Rio Grande do Sul, Porto Alegre.

[2] FARNY, J. A. Concrete Floors on Ground. 3 ed. Portland Cement Association, Skokie, Illinois, U.S.A., 2001.

[3] SILVA, C. V. Contribuição ao estudo do desgaste superficial por abrasão em concretos empregados em pisos. 2011. 180 f. Dissertação (Mestrado em Engenharia) - Escola de Engenharia, Programa de Pós-Graduação em Engenharia Civil, UFRGS, Porto Alegre.

http: / /dx.doi.org/10.25286/repa.v2i3.704 
[4] TARR, S. M.; FARNY, J. A. Concrete Floors on Ground. 4 ed. Portland Cement Association, Skokie, Illinois, U.S.A., 2008.

[5] ACI Committee 302. ACI 302.1R-04 - Guide to Concrete Floor and Slab Construction. American Concrete Institute. Farmington Hills, Michigan, 2004.

[6] ALMEIDA, I. R. Influência da resistência à abrasão do agregado graúdo na resistência à abrasão de concretos de alto desempenho. In: REIBRAC-IBRACON, 42, Fortaleza/CE, 2000.

[7] NEVILLE, A. M. Propriedades do Concreto. Tradução de Salvador E. Giamusso. 2 ed. São Paulo: PINI, 1997.

[8] CHODOUNSKY, M. A.; VIECILI, F. A. Pisos Industriais de Concreto - Aspectos Teóricos e Executivos. São Paulo: Reggenza, 2007.

[9] GARCÍA, A.; FRESNO, D. C.; POLANCO, J. A. Effect of dry-shaking treatment on concrete pavement properties. Construction and Building Materials. v. 22, n. 11, p. 2202-2211, nov. 2008.

[10] HELENE, P.; TERZIAN, P. Manual de dosagem e controle do concreto. São Paulo: PINI, 1992. 349p.

[11] ASSOCIAÇÃO BRASILEIRA DE NORMAS TÉCNICAS. NBR 5739. Concreto - Ensaio de compressão de corpos de prova cilíndricos. Rio de Janeiro: ABNT, 2007.

[12] ASSOCIAÇÃO BRASILEIRA DE NORMAS TÉCNICAS. NBR-12142. Concreto Determinação da resistência à tração na flexão em corpos de prova prismáticos. Rio de Janeiro: ABNT, 2010.

\section{[13] ASSOCIAÇÃO BRASILEIRA DE NORMAS TÉCNICAS. NBR-15558. Concreto - Determinação da exsudação. Rio de Janeiro: ABNT, 2008.}

[14] ASSOCIAÇÃO BRASILEIRA DE NORMAS TÉCNICAS. NBR-7584. Concreto endurecido Avaliação da dureza superficial pelo esclerômetro de reflexão. Rio de Janeiro: ABNT, 2012.

[15] MEHTA, P. K.; MONTEIRO, P. J. M. Concreto: microestrutura, propriedades e materiais. 2 ed. São Paulo: Ibracon, 2014.

[16] MEHTA, P. K.; MONTEIRO, P. J. M. Concreto: estrutura, propriedades e materiais. 3 ed. São Paulo: Ibracon, 2008. 